\title{
Design Research of Wearable Textile Antena
}

\author{
Vikas Kumar, Pramod Singh
}

\begin{abstract}
In this paper comprehensive analysis and design of textile antenna is presented. Low dielectric constant of textile material makes them suitable to be used as substrate. The proposed antenna is fabricated on jeans substrate having dielectric constant of 1.6. The proposed textile antenna has hexagonal shape with microstrip line feed.$U$ shape slot on the patch and defected ground structure is incorporated in the design to obtain desired passband and stopband. The dimension of proposed hexagonal patch is $6.44 \mathrm{~mm}$ and its area is $108 \mathrm{~mm} 2$ which is very compact as compared to previous works.This antenna can be used in two frequency bands one is centered at 3.9 $\mathrm{GHz}$ with bandwidth of $2.5 \mathrm{GHz}$ and another is centered at 8.6 $\mathrm{GHz}$ with bandwidth of $2.4 \mathrm{GHz}$.Along with these passband there is one stop band in the frequency range $5.1 \mathrm{GHz}$ to $8.1 \mathrm{GHz}$. Due to wide bandwidth this antenna can also be called as an ultra wideband antenna with notch band to avoid electromagnetic interference with WLAN (5.1 -5.8 GHz) and satellite application.
\end{abstract}

Index Terms-UWB, TEXTILE ANTENNA, MICROSTRIP FEED

\section{INTRODUCTION}

Antennas are very important part of any wireless communication system. As focus is on small size of wireless devices use of textile materials has been started. Textile not only provides the flexibility but also posses low dielectric constant due to less surface wave losses. [2]. Textile antenna posses less EM radiation deposition due to large planar structure [3]. Textile antenna is very useful for applications such as fire fighters, telemedicine, military people etc. Human body has different curves, fabric easily adapt the shape of body. This property is called draptability.

Federal Communication Commission (FCC) in 2002 approved frequency bands from 3.1 to $10.6 \mathrm{GHz}$ for commercial use of ultra wideband systems [4]. UWB uses very narrow or short duration pulses that result in very large or wideband transmission bandwidths. The UWB frequency spectrum starts from 3.1 to $10.6 \mathrm{GHz}$. UWB applications include wireless communications, medical imaging, radar, and indoor positioning [5] an antenna is said to UWB antenna if its bandwidth is at least $20 \%$ of the centre frequency. It means that if the centre frequency of antenna is $2 \mathrm{GHz}$ then bandwidth must be at least $400 \mathrm{MHz}$

\subsection{Properties Of Textiles In The Design Of Wearable} Antennas

Textile has flat structure and their properties mainly depend on the fibers and the yarns used for weaving them. Textile has pores in between the fibers. In which general behavior such as permittivity and thermal properties is

Revised Version Manuscript Received on August 19, 2019.

Vikas Kumar, M.Tech. Scholar, Department of Electronics and Communication, MIET, Meerut, U.P. India.

Pramod Singh, Associate Professor, Department of Electronics and Communication, MIET, Meerut, U.P. India. determined by knowing how dense is the fiber, what is the volume of air in between the fiber. Textile posses elasticity and flexibility whose density can change with pressure plus, the atoms of water are subsequently trying to change the fibers and this is the reason they are differ in properties. Such characteristic are very useful in improving further its radiation properties; That is why it is crucial to know how they may alter the behavior of the antenna so to reduce undesirable effects. Apart from above, many properties of fabric change the antenna performance and efficiency and are discussed in this paper.

\subsubsection{Dielectric Properties Of The Fabric}

Dielectric properties of textiles have studied by some researchers.

Dielectric property depend on

- Frequency

- Temperature

- Roughness

- Moisture absorption ability

In general, textile posses a very low relative permittivity as they have air in between and due to presence of air relative permittivity approaches to 1 . Relative permittivity of some commonly used textile materials are shown in Table1. Characteristics of a dielectric material can be measured by:

- Cavity Pertubation Method

- MOM Segment Method

- Resonance Method

- Transmission line

Table 1: Relative permittivity of some fabric

\begin{tabular}{|c|c|c|}
\hline $\begin{array}{c}\text { NAME OF } \\
\text { TEXTILE }\end{array}$ & $\varepsilon_{\mathrm{r}}$ & $\tan (\boldsymbol{\delta})$ \\
\hline Cotton & 1.60 & 0.0400 \\
\hline Polyester & 1.90 & 0.0045 \\
\hline Cordoba & 1.90 & \\
\hline Qurtzel & 1.95 & 0.00993 \\
\hline
\end{tabular}

\subsubsection{Thickness Of Dielectric Fabric}

A textile material generally has low dielectric constant and its thickness is major factor to determine bandwidth and input impedance of antenna. For a textile of given dielectric constant its thickness can be used to control the bandwidth. The relation between bandwidth and quality factor is given as: 


\section{Design Research of Wearable Textile Antena}

$$
\text { BW 1/Q }
$$

Where,

$$
\begin{aligned}
& \mathrm{BW}=\text { Bandwidth } \\
& \mathrm{Q}=\text { quality factor }
\end{aligned}
$$

As quality factor is inversely proportional to thickness of the substrate, from equation (1) it is clear that bandwidth is directly proportional to the thickness of the substrate. Thus by increasing substrate thickness bandwidth of a patch antenna can be increased but at the expense of increased size and more surface wave losses which

\subsubsection{Resistivity Of The Electro Textile}

For fabric antenna design, the conductivity is the important parameter .It is given by

$$
\sigma=\frac{1}{\rho_{s . t}}
$$

Where,

$$
\begin{gathered}
\sigma=\text { conductivity } \\
\rho_{s}=\text { surface resistivity }
\end{gathered}
$$

To get low electrical losses fabric having low surface resistance surface opposition should be selected. This increases efficiency of the textile.

\subsubsection{Moisture Inside The Fabrics}

Due to absorption of water textile swell in all direction, due to which they become tight. Due to tightness dimensions of fabric get smaller. The changes in size due to moisture absorption change antenna parameters and thus change the behavior. Moist fabric also has different dielectric as compared to dry fabric as water take place of air in between the fabric. [8]

Therefore the textile which has less moisture absorption ability is better choice for the selection of textile substrate and same is applied to conductive part.

\subsubsection{MECHANICAL BENDING}

Due to flexibity and elasticity textile material easily take the shape of human body. But due to bending of textile according to human body changes their electromagnetic properties and result in antenna detuning

Geometrically, the increase in length $\Delta \omega$ as a result of bending of radius $\mathrm{R}$ is given according to (2)

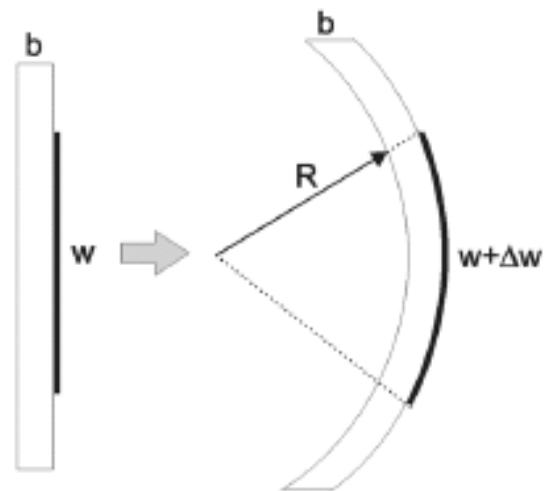

Fig 1: elongation due to bending [6]

$$
\frac{\Delta w}{w}=\frac{b}{2 R+b}
$$

\subsection{Types Of Textile Materials}

\subsubsection{Electrically Conductive Fabric}

The designing of textile antenna started with selecting proper material for substrate and patch. Many conductive textiles are easily available and have been used by many researchers in designing the antenna. Due to the planar structure and light weight textile antenna gat easily integrated into clothing. For good result fabric need to meet the following requirement.

- The fabric should posses flexibility.

- Fabric which can be stretched can easily withstand deformation.

- The opposition should not change over the entire surface of the textile.

\section{Types Of Conductive Textiles}

\section{Nickel-Plated Fabric}

This type of fabric is flexible due to which it can be easily used in clothing. Since knitted plated fabric get easily stretch antenna result get alter.

According to simulation result for this type of fabric, there is a loss in conductive material efficiency. The fall in conductive material efficiency is about $99 \%$ for copper tape to $45 \%$ for knitted fabric. But comparison to copper tape fabric provide draptibility.

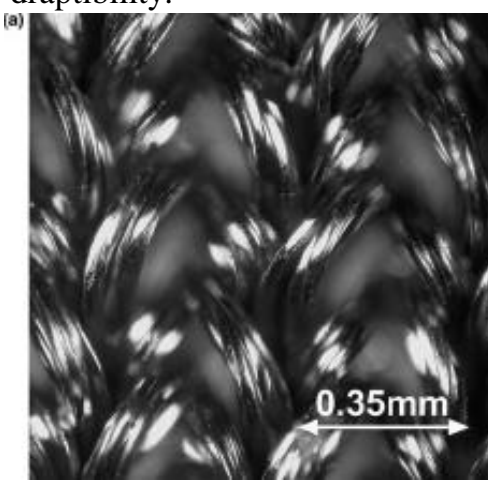

Woven Fabric

In this type of textiles fabric weaving is done after plating the threads. The advantage of using woven fabric is that they are less stretchable but they lack flexibility. This type of fabric has low electrical resistance. 
Fig. 3: Woven Fabric [7]

TABLE2: Properties Of Conductive Knitted And Woven Fabric [12]

\begin{tabular}{|l|c|c|}
\hline CHARACTERISTICS & $\begin{array}{c}\text { Fiber of } \\
\text { type 1 }\end{array}$ & $\begin{array}{l}\text { Fiber of } \\
\text { type 2 }\end{array}$ \\
\hline Width & $\begin{array}{c}0.5 \mathrm{~mm}+10 \\
\%\end{array}$ & $0.15 \mathrm{~mm}$ \\
\hline Yarned polymers & Polyamaride & Polyaride \\
\hline thread intensity & $0.3 \mathrm{~mm}$ & $0.2 \mathrm{~mm}$ \\
\hline Fibre & $6.0 \mathrm{~mm}$ & $12.0 \mathrm{~mm}$ \\
\hline Mass & $179 \mathrm{~g} / \mathrm{m}^{2}$ & $70 \mathrm{~g} / \mathrm{m}^{2}$ \\
\hline Covering & $\mathrm{Silver}$ & $\mathrm{Nickel}$ \\
\hline Opposition value & $<1 \Omega \mathrm{m}$ & $0.02 \Omega \mathrm{m}$ \\
\hline
\end{tabular}

\subsubsection{Textile Substrate}

The antenna using textile as a dielectric material is fabricated by taking substrate in between the metallic radiator and the bottom plane. (see Fig. 4).

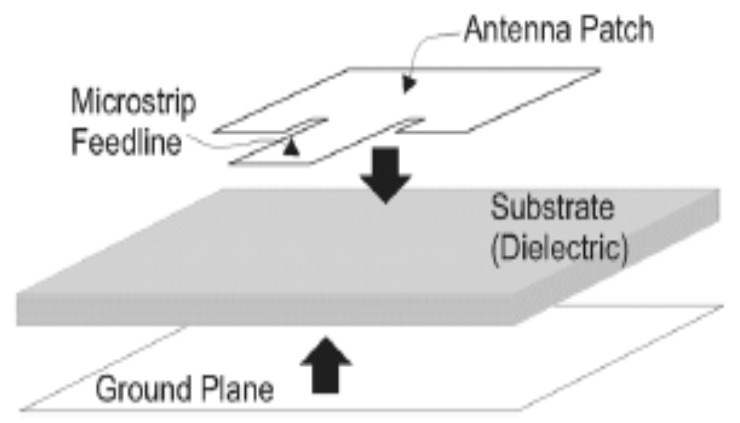

Fig 4: Different component of antenna with feed line [6]

Thickness of substrate should not change up to few millimeters and it should have low permittivity due to which antenna patch enlarges. It is very important to select a proper textile substrate for the fabric antenna. Properties to be taken into consideration when selecting dielectrics are

- There should be homogeneity

- Material should have large capacity to absorb moisture

- Material should posses large adhesive properties

In 2005 Salonen et al. [9] presented a GPS antenna which uses five types of different textile materials for substrate. In 2010, S. Sankaralingam and B. Gupta [10] proposed fully fabric wibro antenna. In this work they used three different textiles as substrate
TABLE 3: VARIOUS TEXTILE MATERIAL USED AS SUBSTRATE

\begin{tabular}{|c|c|c|}
\hline TEXTILE MATERIAL & $\begin{array}{c}\text { DIELECTRIC } \\
\text { CONSTANT }\end{array}$ & $\begin{array}{c}\text { LOSS } \\
\text { TANGENT }\end{array}$ \\
\hline JEANS & 1.6 & 0.025 \\
\hline ARAMID FABRIC & 1.75 & 0.015 \\
\hline $\begin{array}{c}\text { POLYDIMETHYLSILO } \\
\text { XANE (PDMS) }\end{array}$ & 3 & $<0.01$ \\
\hline BAKHRAM & 1 & - \\
\hline COTTON & 1.7 & 0.025 \\
\hline
\end{tabular}

\section{DESIGN OF UWB TEXTILE ANTENNA\& RESULTS}

The proposed microstrip patch textile antenna operates in UWB range with two pass bands and one stop band. It is microstrip monopole antenna with regular hexagonal shaped patch and reduced ground plane with a notch. The patch and ground plane are conducting in nature and use copper tape to make it conducting and flexible. In between patch and ground planes Jeans textile is used as substrate material. Characteristics features of substrate material are shown in Table 4.

TABLE 4

\begin{tabular}{|l|c|}
\hline \multicolumn{1}{|c|}{ PARAMETERS } & VALUES \\
\hline Thickness & $1.6 \mathrm{~mm}$ \\
\hline Relative permittivity & 1.7 \\
\hline Loss tangent & 0.25 \\
\hline
\end{tabular}

\subsection{Uwb Antenna Design Considerations}

Front and back view of proposed UWB antenna is shown in fig.(5). It consists of regular hexagonal patch with symmetrical U slot and reduced ground plane with a narrow notch at the centre of the upper edge. Physical dimensions of the proposed structure is shown

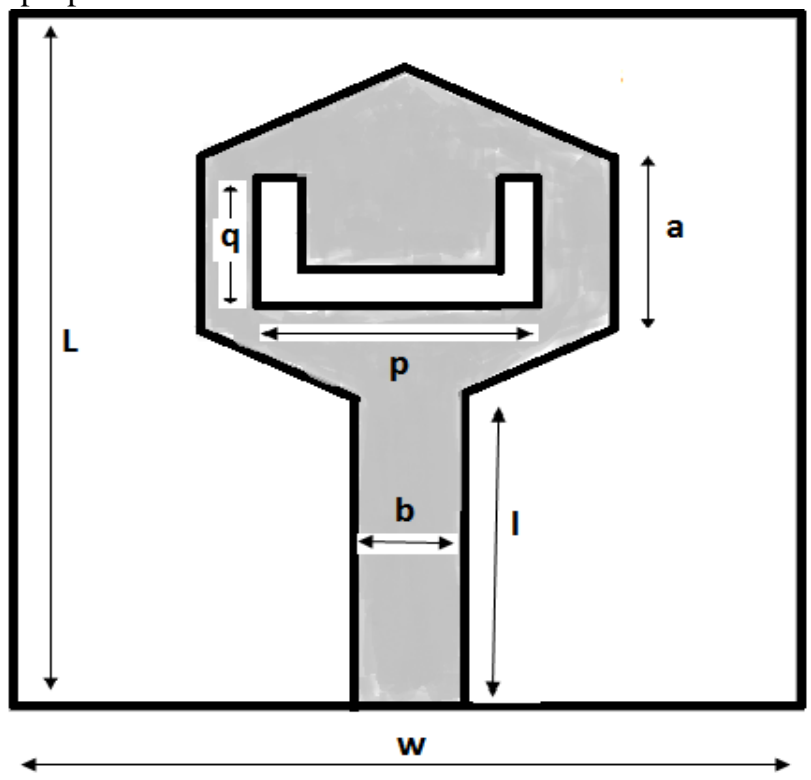

Published By: 


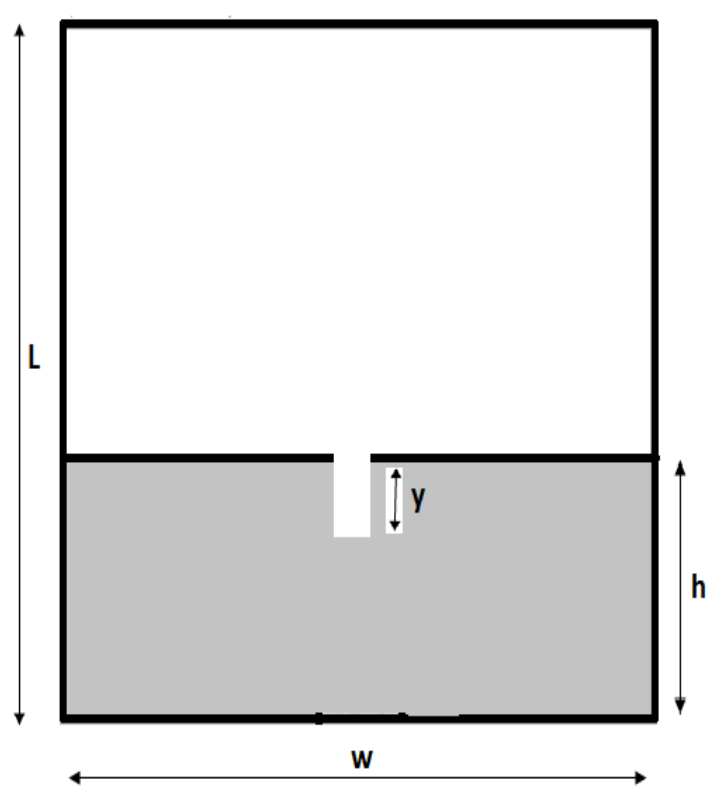

Fig 5: Geometry of proposed antenna

TABLE 5 DIMENSIONS OF PROPOSED UWB WEARABLE

\begin{tabular}{|c|c|c|c|}
\hline Parameter & Unit (mm) & Parameter & Unit (mm) \\
\hline L & 29 & 1 & 11.5 \\
\hline W & 28 & b & 3 \\
\hline a & 6.44 & h & 9 \\
\hline P & 4 & Y & 3 \\
\hline Q & 6 & & \\
\hline
\end{tabular}

\subsection{Results and Discussion}

The proposed hexagonal textile monopole antenna with $\mathrm{U}$ shaped slot on the patch and notched ground plane is simulated on HFSS software. The major objective of this work is to design a flexible compact UWB antenna with minimum electromagnetic interference with existing narrowband applications.

Figure (6) shows the return loss plot of the proposed antenna. The proposed antenna shows good impedance matching. The proposed antenna resonates at two frequencies hence serves as a dual band antenna. This structure has two pass bands one is centered at $3.9 \mathrm{GHz}$ and another is centered at $8.6 \mathrm{GHz}$. At $3.9 \mathrm{GHz}$, the return loss is $-25 \mathrm{~dB}$ and at 8.5 $\mathrm{GHz}$, the return loss is $-18.5 \mathrm{~dB}$.

At $3.9 \mathrm{GHz}$ the minimum required bandwidth for an UWB antenna is $780 \mathrm{MHz}$ while the bandwidth of proposed model is $2500 \mathrm{MHz}$. For centre frequency of $8.6 \mathrm{GHz}$ minimum required bandwidth is $1.72 \mathrm{GHz}$ while the bandwidth of the proposed model is $2.4 \mathrm{GHz}$. There is a notch band between $5.2 \mathrm{GHz}$ to $8 \mathrm{GHz}$ which avoid interference from WLAN and other military related applications.

The frequency range of proposed antenna can also be verified from the plot of voltage standing wave ratio (VSWR) which is shown in fig (7). Figure 8(a) and (b) shows the 2D radiation patterns of the proposed structure at resonant frequencies

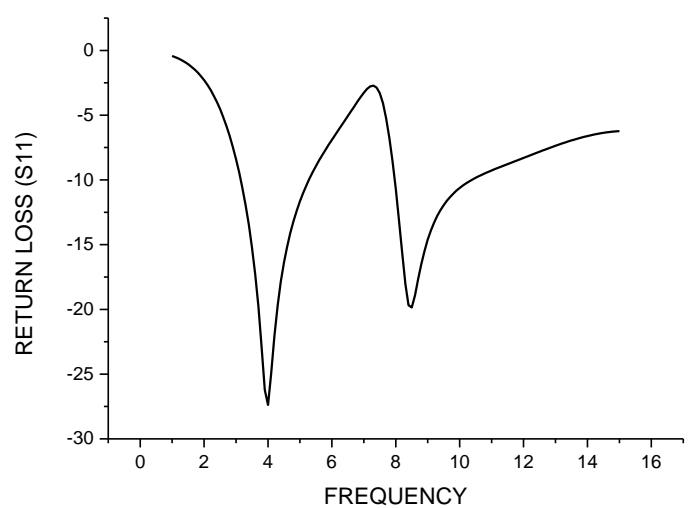

Fig. 6: Plot of Return Loss (S11) for Proposed Antenna

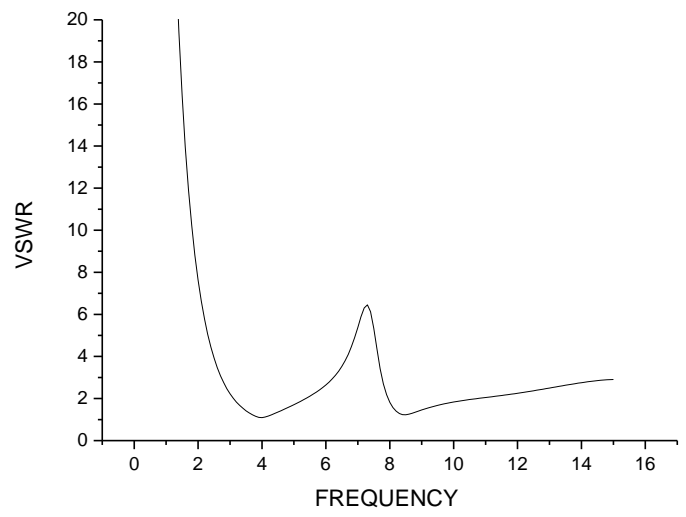

Fig. 7: Plot of VSWR for Proposed Antenna

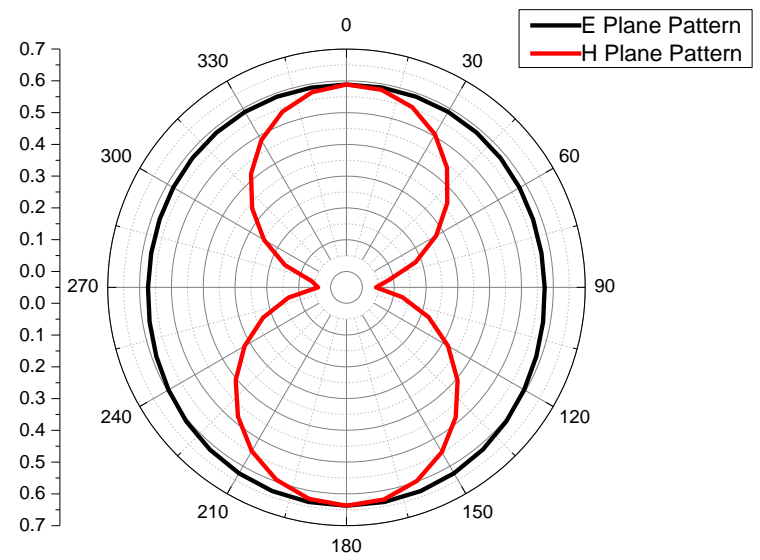

Fig 8 (a): E-Plane and H- Plane Pattern at 3.9 GHz

Published By: 


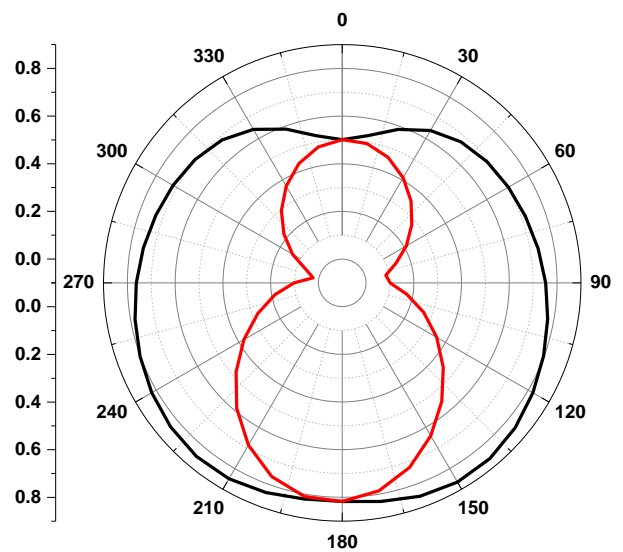

Fig 8 (b): E Plane and H Plane Pattern at $8.7 \mathrm{GHz}$

\section{Comparison of Proposed Antenna with Several Existing Designs}

\begin{tabular}{|c|c|c|c|}
\hline S. No. & Reference & Substrate Area & Notch Band \\
\hline 1 & {$[19]$} & $1050 \mathrm{~mm}^{2}$ & WLAN around 5.5 GHz \\
\hline 2 & {$[20]$} & $896 \mathrm{~mm}^{2}$ & $5-5.6 \mathrm{GHz}$ \\
\hline 3 & {$[21]$} & $840 \mathrm{~mm}^{2}$ & $5.15-5.825 \mathrm{GHz}$ \\
\hline 4 & {$[22]$} & $1120 \mathrm{~mm}^{2}$ & $\begin{array}{c}3.2-3.7 \quad \mathrm{GHz} \text { \& } 5- \\
5.9 \mathrm{GHz}\end{array}$ \\
\hline 5 & {$[23]$} & $1305.6 \mathrm{~mm}^{2}$ & WLAN 5 GHz \\
\hline 6 & $\begin{array}{c}\text { Proposed } \\
\text { Work }\end{array}$ & $812 \mathrm{~mm}^{2}$ & $5.2-8 \mathrm{GHz}$ \\
\hline
\end{tabular}

The results obtained from the proposed structure is compared with the previous similar works and from the above table it is clear that the proposed design uses least substrate area to be used as UWB antenna with notch band for WLAN.

\section{CONCLUSION}

A compact microstrip monopole textile UWB antenna is designed with two pass bands and one notch band. This structure uses regular hexagonal shaped patch antenna with partial ground plane. Due to insertion of U shaped slot on the patch and notch cut on the ground plane this structure is able to provide two wide pass bands centered at 3.9 and $8.7 \mathrm{GHz}$, while a notch band to avoid possibility of electromagnetic interference with WLAN (at $5 \mathrm{MHz}$ ) and other satellite applications. From the comparisons it is found that this design is using least substrate area.

\section{REFERENCES}

1. "A Compact Microstrip Antenna for UWB Applications" Neeba George and B. Lethakumary Department of Electronics and Communication, Mahatma Gandhi University College of Engineering, Muttom P.O., Thodupuzha, Idukki,Kerala 685 587, India; Corresponding author: letha@ucet.ac.inG. O. Young, "Synthetic structure of industrial plastics (Book style with paper title and editor)," in Plastics, 2nd ed. vol. 3, J. Peters, Ed. New York: McGraw-Hill, 1964, pp. 15-64.

2. "Design and Analysis of High Gain UWB Textile Antenna for Wearable Application" by Oshin S.P, Swetha Amit, 2017 2nd IEEE International Conference On Recent Trends in Electronics Information \& Communication Technology (RTEICT), May 19-20, 2017, India

3. "Antenna Theory Analysis and Design", Third Edition by A. Balanis

4. P.Salonen, Y.Rahmat-Samii, H.Hurme and M.Kivikoski, "Dual band wearable textile antenna," in Proc. IEEE ,APS Int.Symp., Montery, CA, Jun. 2004, vol. 1, pp. 463-446.

5. C.Hertleer, H rogier, senior member IEEE and L Van Langehore" A
Textile Antenna for Protective Clothing"

6. "Design and Characterization of purely Textile Patch Antennas" Ivo Locher, Student member, IEEE, Maciej Klemm, IEEE transaction on advanced packaging, November 2006.

7. "Wearable antennas for Body Area Networks",Peter S.Hall and Yang Hao ,University of Birmingham UK ,Microstrip and Printed Antennas ,2011 John Wiley \& sons Ltd.

8. "Textile Materials for the Design of Wearable Antennas" A Survey Rita Salvado Caroline Loss, Ricardo Gonçalves and Pedro Pinho, 2012

9. Y.Ouyang, E.Karatyianni and W.Chappell,"Effect of fabric patterns on electrotextole patch antennas," in proc.IEEE AP-S Int.Symp.,Washington, DC,Jul.2005, vol.2B, pp.246-249.

10. "Use of Electro - textiles for Development of Wibro antennas" by S Sankaralingam and B.Gupta, 2010, Department of Electronics and Tele communication engineering,Jadavpur university, Kolkata, India.

11. Morton, W.E.; Hearle, W.S. Physical Properties of Textile Fibres, 4th ed.; Woodhead Publishing: Cambridge, UK, 2008.

12. J. W. Balde, "Packaging at the turning point -Technology and Management issues," in Proc. IMAPS France 2001, May/June 2001, pp. 22-24.

13. "Microstrip and Printed Antennas New Trends, Techniques and Applications" by Debatosh Guha and Yahia M.M. Antar, John Wiley and sons publication, 2011

14. "Design and Analysis of High Gain UWB Textile Antenna for Wearable Application" an IEEE paper by Oshin S.P, Oshin S.P, M.Tech, Digital Communication Engineering, RIT, and Bangalore, India.

15. Mai A. R. Osman, M. K. A. Rahim, M. Azfar. A., K. Kamardin, F.Zubir, and N. A. Samsuri, "Design and analysis UWB wearable textile antenna,"Proceedings of the 5th european conference on antennas and propogation (EUCAP) IEEE Conference publication, 2011.

16. A.Tronquo, H.Rogier, c.Hertleer, and L.Van Langenhove, "Arobust planar textile antenna for wireless and e-textile antennas," in Proc. IET Seminer Antennas and Propagation for Body-Centric Wireless Propagation. Lett, vol.6, pp. 392-395

17. Gang Zou, Hans Gronqvist, Johan Liu, "Characterization of Liquid Crystal Polymer for High Frequency System in-a-Package Applications."

18. D.A. Rudy, J.P. Mendelsohn and P.J. Muniz, "Measurement of RF Dielectric Properties with series resonant microstrip elements." Microwave J. pp 22-39Mar.1998.

19. E. Pancera, D. Modotto, A. Locatelli, F. M. Pigozzo, and C. De Angelis, "Novel design of UWB antenna with band notch capability," in Proc. Eur. Conf. on Wireless Technologies, 2007, pp. 48-50.

20. J. -B. Jiang, Z. -H. Yan, and C. Wang, "A novel compact UWB notch filter antenna with a dual-y-shaped slot," Progrress in Electromagnetic Resarch Lett., vol. 14, pp. 165-170, 2010

21. X. L. Bao and M. J. Ammann, "Printed band-rejection UWB antenna with H-shaped Slot," in Proc. Int. Workshop on Antenna Technol. Small and Smart Antennas Metamaterials and Applications (IWAT), 2007, pp. 319-322.

22. Y. F. Weng, S. W. Cheung, and T. I. Yuk, "Ultrawideband antenna using CPW resonators for dual-band notched characteristic," in Proc. Int. Conf. on Wireless Commun. and Signal Processing (WCSP), 2009,pp. 1-4

23. S. Barbarino and F. Consoli, "UWB circular slot antenna provided with an inverted-L notch filter for the $5 \mathrm{GHz}$ WLAN band," Progr. Electromagnetic. Res., vol. 104, pp. 1-13, 2010. 